\title{
Strategic Framework for Portuguese School Libraries: 2014-20
}

\author{
Elsa Conde \\ School Libraries Network Agency \\ Travessa Terras de Sant'Ana, $15 \quad$ 1250-269 Lisboa \\ Portugal \\ elsa.conde@rbe.mec.pt
}

\begin{abstract}
The main purpose of this paper is to present the School Libraries Network Program of the Ministry of Education and its strategy concerning the creation and the implementation of a National Strategic Framework for School Libraries: 20142020.

According to "Europe Strategic 2020", the School Libraries Network Program (SLNP) conceived an action plan to align with and contribute to the European goals for education.

To respond to the current challenges, due to the digital revolution and the way we deal with information and acquire knowledge, the educational systems need, more than ever of strong school libraries, able to teach and support students achieving a good educational attainment and the skills essential to the future. With this professional paper we propose to underline the need of new managing tools and a new strategic thinking and discuss how this standards framework can contribute to the progress of the school libraries in a rapidly changing world, a world much more demanding and much more focused on results, that have an impact on students' achievement and make a difference in their lives.
\end{abstract}

Keywords: School libraries; School Libraries Network Program; Strategic management; Library standards; Literacies

School Libraries Network Programme ( SLNP) was launched in 1996, Its main goal was to install and develop libraries in state schools at every level, supplying its users with the necessary resources to read, access, use and produce information, regardless the format. Now all schools have a library or, in very small schools a library service and the great challenge is to strengthen this network, accompanying social and technological changes and placing it at the service of the improvement of education and learning.

Thus, following the "Europe Strategy 2020", the SLNP conceived a strategic framework to align with and contribute to the European goals for education.

The Strategy Europe 2020 sets out the main objectives of the European Union to be achieved in the period 2014-2020. The plan, whose goals are to improve the levels of education in each member state, raised the need for definition by the SLNP of a number of areas and priority lines of intervention, in order to guide their action and contribute to the achievement of the goals set to Portugal in this domain.

The national targets in the area of education point to the reduction in the rate of early exit of the education and training systems and the improvement of the qualifications and skills of the Portuguese population, through the achievement of different goals: 
- Raise the results of national tests in Portuguese and Mathematics;

- Reduce the retention and drop-out rates;

- Increase the rate of schooling in the Secondary Education;

- Strengthening vocational education and other vocational and education/ training courses in Basic and Secondary Education;

- Reorganizing, streamlining and qualify the School Network;

- Involve and engage schools and educational communities in achieving the national goals of improving the basic skills of the students and the extension of compulsory schooling.

School libraries are an important partner of any strategy to improve education and to combat school drop-out and failure, so the SLNP can help to ensure that these goals are achieved by associating its own development strategy to this overall plan.

To this extent, the strategic framework of the SLNP has defined a set of standards for school libraries to be achieved within the timeframe of 2014-2020, according to the Europe 2020 Strategy that Portugal and the Ministry of Education and Science have signed:

1. Places for knowledge and innovation, able to incorporate new pedagogical practices.

2. Spaces for social integration, essential to combating exclusion and school dropout.

3. Places for training and development of reading competence, condition of all knowledge.

4. Spaces diffusers of the pleasure of reading, essential to the construction of reading habits.

5. Teaching areas, essential to the training for the digital, media and information literacy.

6. Centres of pedagogical support, crucial for the fulfilment of goals of school education.

7. Flexible environments adapted to technological change and to users needs.

8. Structures led by skilled teacher-librarians, able to respond to functional and pedagogical requirements of the school.

9. Information services with digital contents and technological resources able to respond to social changes.

10. Dynamic and sustained networks with consistent practices, embedded in the community.

11. Cooperation systems with the society, sharing resources and knowledge.

12. Inclusive organizations, guaranteeing equal access to services and information resources.

13. Management units, oriented for quality and excellence. 


\section{Implementation of the Strategic Framework of the SLNP}

The SLN is currently made up of more than 2,400 libraries. More than one million students have library in their schools. Following the implementation of policies to ensure the value and the excellence of these libraries, the SLNP purpose is to promote and monitor all the libraries in a dynamically and systematic way and to take the appropriate measures to the challenges they face, promoting the continuous improvement of their services.

In this context the program decided to establish a set of standards and action lines that define the vision and the path to pursue by the libraries and guide the global policy development of the SLN for the period 2014-20.

The Strategic Framework is, in this sense, a guiding instrument for the management of the SLN and the school libraries. Its standards, for which libraries must progressively tender, and its lines of action act as guidelines and require the coordinated action and the compromise between the SLNP and the schools.

The creation of the Strategic Framework has been designed in conjunction with two other documents, both very important to operationalize its actions in the ground:

- Learn with the School Library: learning standards associated with the work of the school libraries in Pre-school Education and in Basic Education.

- School Library Evaluation Model: 2014-2017;

The document Learn with the School Library establishes a set of performance standards associated with reading, information and media competencies, essentials for learning and students' integral education, which school libraries have to develop. The document aims to promote the integration of knowledge, skills and attitudes related to these literacies in educational activities and curricula developed with the library, providing it with the planning, operationalization and measurement tools necessary to this purpose. It is, therefore, an important work instrument, that makes easier to obtain data and evidence that demonstrate the actions of library in these areas and attest its impacts in students' learning and global education.

The School Library Evaluation Model (SLEM) seeks to know the results of the activity of libraries in the educational process, the degrees of efficiency and effectiveness of the services provided and the levels of user satisfaction, to improve its overall performance. The model has four domains, related to the action areas of the library: in the support of the curriculum and the development of literacies (A); in promoting the skills and habits of reading (B); in projects and partnerships (C); and in the management of the resources and services (D).

The SLEM 2014-17 corresponds to the new phase of evaluation of school libraries, accommodating the experience of the previous cycle. The main changes with respect to the previous edition, now updated, consist in establishing a simultaneous evaluation of the four domains; in the creation of alternating periods of evaluation and improvement, giving time to the libraries to develop actions that enable them to overcome the weaknesses detected; and in a greater value given to the appreciations of users about the benefits of their interaction with the library and its impacts.

The relationship of this document with the SLN Strategic Framework led to the inclusion of the strategic framework descriptors in the four domains evaluated, to indicate the level of 
excellence to achieve in each domain. It is intended that, by the end of the evaluation cycle of 2014-2017, all libraries have a rating level assessed equal to or greater than 3 (the scale goes from 1 to 4 points) and until 2020, it is expected that libraries continue this improvement, reaching the standards set in the Strategic Framework.

The Strategic Framework 2014-2020 works in this way, not only as a guide for the SLN activity but also as a guiding instrument for the improvement plans of the libraries, carried out in the context of the use of SLEM.

Thus, monitoring the evolution of the libraries and the implementation of the action lines defined by the SLNP will be done in two distinct periods, related to the evaluation process in schools: the first will take place until 2017, coinciding with the end of the evaluation cycle defined in the SLEM; the second will integrate the evaluation results obtained until 2020, with the ending of the Program Portugal 2020 and the term of the Strategic Framework.

\section{Description of the Strategic Framework of the SLNP: vision and priorities}

School libraries have undergone great transformation processes derived from global changes, like technological developments, that revolutionized the modes of access, management and production information, and proximity factors related to the changes that have occurred in the context of the school and the educational system.

To respond to the current challenges, due to the digital revolution and the way we deal with information and acquire knowledge, the educational systems needs, more than ever, of strong school libraries, able to teach and support students achieving a good educational attainment and the skills, essential for the future.

SLNP aims to contribute to these purposes and continue its mission of development of libraries, adapting policies, objectives and modes of intervention to the social changes and to the requirements of the new information culture.

The results already achieved expressed in the creation of a set of facilities, equipments, information systems, collections and professionals, able to make a difference and influence positively in the learning and students' global education advising the continuation of a strong bet on the Program.

After a long trajectory the SLN reached a stage of maturity, but it is necessary to continue to invest in consolidating and ensuring their quality, promoting the upgrade of the existing resources for the current digital and technological requirements, the creation of educational services with visible impact in the life of the school and in the success of students, the continued improvement of levels of literacy and skills and the offer of innovative spaces of knowledge, personal growth and citizenship.

It was on this background and with this determination that it was established a standards of excellence framework, which act as a reference for the conduct of the work of school libraries and the strategy of the SLNP until 2020.

Below, the profiles to achieve by school libraries in different fundamental dimensions are translated and transcribed as well the lines of action to pursue by SLNP for each of these dimensions.

1. Places of knowledge and innovation, able to incorporate new pedagogical practices. 
Libraries are nuclear structures of the schools, provided with resources, services and technologies, able to contribute for the enrichment of the curriculum and teaching practices. Libraries are spaces where we read, research, have access and use all kind of information and explore varied environments, resources and learning techniques. Libraries are places of learning and innovation, inducing new modalities of use and school work, individual and autonomous, in small groups and with the classes, in formal and non-formal educational contexts, in presence and online.

Lines of action:

- Provision of educational contents and computer applications to support research, communication and students schoolwork.

- Training of human resources in areas related to the curriculum and the information, media and digital literacy.

- Follow-up of the implementation of the benchmark Learn with the School Library.

2. Spaces for social integration, essential to combating exclusion and school drop-out.

Libraries promote equal opportunities in the access to knowledge and citizenship. They stimulate the curiosity for literature, the arts and science, acting as places of enjoyment and educational and cultural development. Promote the meeting and sharing of interests and knowledge, social relations and the democratic experience. They are learning, support and testing laboratories, therefore developing inclusion practices that combat exclusion, failure and drop-out and constitute an important social asset.

Lines of action:

- Adaptation of the work of libraries and expand their capacity to respond to new types of audiences and needs.

- Framing school libraries in the global policies and strategies for combating failure, exclusion and students' drop-out.

- Strengthening the social, cultural and educational value of libraries in schools and communities, through initiatives and projects of social intervention.

3. Places of training and development of reading competence, condition of all knowledge.

The libraries provide a regular and close contact with books and the practice of reading, while privileged instruments of learning and training of reading comprehension. Learning to read and reading to learn are basic principles of formation of competent readers. These skills are structural and nuclear to knowledge acquisition and determinant to the educational background of the students. The library contributes significantly through its mediation and action to the qualitative improvement of the learning and the mastery of reading skills.

Lines of action:

- Production of materials and instruments to support the work of the libraries in the areas of learning to read and of readers training.

- Enhanced support for projects and contests geared towards the development of reading skills.

- Participation in initiatives to stimulate the relationship between reading skills and other domains of knowledge - Science, Literature, Art, ... 
4. Spaces diffusers of the pleasure of reading, essential to the construction of reading habits.

Open to creativity and knowledge, libraries encourage the work around the book, reading and different expressions associated with reading, assuming themselves as places of personnel construction and training of critical and autonomous readers. School libraries create a culture of reading, printed and digital, exploring resources, technological equipments and strategies capable of enriching the experiences of each reader and of promoting the taste and the pleasure of reading.

Lines of action:

- Promotion of updated information resources, by encouraging the introduction of new lending forms and reading devices.

- Partnership with promoters of autonomous reading programs and recreational, in particular the National Plan for Reading.

- Participation in research studies on new ways to read.

5. Teaching areas, essential to the training for the digital, media and information literacy.

Libraries promote the collaborative work with teachers and participate in projects and in educational activities, contributing for the improvement of students' results and for resolving learning problems. They are living and working environments where training and learning pathways stimulate the students interaction with technologies and diversified sources of information. They occupy a vital place in school as they encourage the training for digital media and information literacy, preparing students for the research, use, production and communication of information and for the safe and informed participation in social networks.

Lines of action:

- Follow-up of the implementation of the benchmark Learn with the School Library.

- Articulation with other services of the Ministry of Education and Science, with the purpose of integrating the library into the curriculum and into programs or activities associated with the development of different skills.

- Partnerships with universities and other organizations for the production of contents, training and studies.

6. Centres of pedagogical support, crucial for the fulfilment of goals of school education.

To fulfil their mission, the libraries require a planning that establishes relations with the educational project and the plan of activities of the school. Investment in articulation with other structures of the school and in particular with the principal is also essential. Libraries play an open-door policy, participating in school activities, educational support, study support, curricular enrichment activities, projects, clubs, occupation of leisure time and other recreational and cultural initiatives.

Lines of action:

- Adequacy of policies, guidelines and management of libraries to changes in school and in the education system.

- Coordination with other services of the Ministry of Education and Science, to include the school library and its goals in the general educational measures.

- Promotion of an institutional dialogue with the schools management bodies, to improve their educational service. 
7. Flexible environments adapted to technological change and to user needs.

Libraries are workspaces face-to-face and online environments of distance work. The dilution of the boundaries that separate media and functional zones and the emphasis on production and networking change the traditional library setting. The libraries are counting on more workstations provided with devices and software for research activities, information processing and content production. The exponential growth of online digital content, equipment portability and userfriendly handling of production and communication tools transform the way users relate to information and flexible physical and virtual access to resources, services and technologies.

Lines of action:

- Revision of the technical guidelines and conditions for the installation and equipping of school libraries.

- Conversion of the physical space of the libraries and upgrade of equipment and software.

- Contacts with institutions and companies providing furniture, equipment, software and other specific goods.

8. Structures led by skilled teacher-librarians, able to respond to functional and pedagogical requirements of the school.

The teacher-librarians, supported by teaching and non-teaching staff, play an active role in the processes of management, leadership and innovation in schools. They have a crucial pedagogical intervention in the school life of students and in the training for reading and for digital and information literacy, with impact on learning and educational success. They develop cultural activities, essential to the acquisition by pupils of personal and social skills and the appropriation of school library by the community. They are information managers, assuming a fundamental mediator function in access, validation, and dissemination of information and creation of contents.

Lines of action:

- Ensuring institutional procedures which ensure the affectation of qualified professionals to school libraries.

- Further training of teaching and non-teaching staff, partnering with Training Centres Associations of Schools, Universities and other training providers.

- Definition of human resources management policies to ensure the smooth operation of the libraries.

9. Information services with digital contents and technological resources able to respond to social changes.

Libraries are resource-rich environments of reading and learning, adequate to intellectual interests and the needs of the school community. Technological developments and changes in the publishing market, relating to copyright and the methods of acquisition and loan, revolutionized the ways of access and dissemination of information, reinforcing the need for change of the collections and of the practices associated with their management.

Lines of action .

- Incorporation of results of studies and recent practices, to pursue the cooperative management of the collections, the acquisition of documents in digital formats and the implementation of electronic loans. 
- Promote interlibrary partnerships and pursuing the creation policy of digital libraries and collective catalogs.

- Revision of the guidelines of the SLN on the management of the collection.

10. Dynamic and sustained networks with consistent practices, embedded in the community.

The relationship of school libraries with each other and with municipal libraries accompanied and institutionally supported at the municipal level, is essential for the balanced and sustainable growth of the libraries. Libraries take advantage of applications, contests, projects, and other local initiatives and from SLN, ensuring the rooting, the visibility and the dissemination of consistent and sustainable practices at school and in the community.

Lines of action:

- Development and consolidation of local networks - collectives catalogs, portals, cooperation projects, training, ...

- Increase and diversification of partnerships with communities, involving families and other interlocutors.

- Provision of platforms and information systems that facilitate the creation of networks and systems of cooperation at the local level.

11. Cooperation systems with the society, sharing resources and knowledge.

The cooperation of school libraries with other organizations (universities, libraries, museums, archives, associations, companies,...) and the participation in collective projects of different size and scope, are an indispensable asset to their value and integration in society. At a time when the networks and digital tools favour the conjugation of synergies and the implementation of common projects and activities, the library is strengthened by the sharing of resources, by establishing partnerships and by taking advantage of collaborative work.

Lines of action:

- Consolidation of partnerships, projects and cooperation agreements established with different entities.

- Creation of new partnerships at national and international level.

- Elaboration of studies and evaluation reports on results of projects developed.

12. Inclusive organizations, guaranteeing equal access to services and information resources.

Spaces of inclusion, free and open to all, libraries ensure equal access to equipments, diversified information resources and services, able to respond to specific needs of different users. The libraries are, by their nature and mission, a natural base of support for students with special educational needs, with differentiated curricula or with other forms of individualized treatment.

Lines of action:

- Support for updating and continued diversification of information resources, in order to accompany the variety of interests and needs of different audiences.

- Creation of physical and technical conditions to make libraries able to provide differentiated answers to students with special educational needs or other specific needs - professional, vocational courses, education and training, other. 
- Strengthening of partnerships and projects promoting equal access to information and social inclusion.

13. Management units oriented for quality and excellence.

The organizational and pedagogical suitability of libraries to face the challenges posed by the school and by the society constitutes a determining factor for the quality of its functioning. The paradigm shift in the forms of access, use and communication of information redirects the focus of libraries towards strengthening the role of education and training. This approach requires the adoption of new management practices, in direct link with the curricular goals of the schools and the learning of students. The efficiency and effectiveness of this management policy demand a culture of evaluation, based on evidence and on a strategy of continuous improvement.

Lines of action:

- Dissemination of good practices and results of the libraries.

- Carrying out studies showing the impact of libraries.

- Support for the improvement and development plans of the libraries, particularly those which present major difficulties.

\section{Monitoring and evaluation of the Strategic Framework of the SLNP}

The implementation of the Strategic Framework is operationalized through annual action plans that contemplate the objectives and measures to achieve, according to the intervention lines previously defined.

The monitoring of the entire process will take place in two interconnected levels:

- the first, concerning the achievement of the annual initiatives under the direct responsibility of the SLNP;

- the second concerning the continuous measurement of the results arising from the application of the SLEM in the schools.

Monitoring the strategic framework make it possible to adapt the different actions to the evolution of the results and track the success of convergence of libraries with the established standards. This route can be affected by conditions and factors of uncertainty, forcing adjustments of both the objectives and the timetables laid down.

To carry out this work, the SLNP will use its information system and its coordination services operating on the ground. In addition, the Program will benefit from the support and collaboration of other services of the Ministry and of their partners, as well as other individual contributions.

The operationalization of the Strategic Framework should include accomplishing indicators that allow knowing the execution scope of the measures and objectives outlined in each year. In schools, the use of the SLEM will provide, in turn, results that will indicate their level of performance over the evaluation cycle and assess the degree of success of the developed improvement processes.

The carrying out of studies, the survey of good practices, the exchange of ideas and experiences, specialized training, the production of research theses, networking with other organizations, the conduct of pilot projects (such as, for example, the use of the benchmark Learn with the School Library) will also be encouraged for this purpose. 
Finally, it should be noted the interest of the external evaluation of the SLNP, held by ISCTE - Lisbon University Institute in 2009 , which should be continued as a quality factor and improvement, sustainability and projection of the SLN. The possibility of making an external evaluation on the implementation of the Strategic Framework could be an asset to its validation.

In conclusion, we would like to note that the importance of this Strategic Framework does not end with its results. Through its implementation, we hope to contribute, not only for a more effective management of the SLN but also for an increase in their ability to seize the opportunities and meet the challenges facing libraries in the 21 st century, and continue to demonstrate the indispensable value of a public policy for school libraries, reading, new skills and the social inclusion that they provide.

\section{References}

Lançar a Rede de Bibliotecas Escolares (1996). Coord. Isabel Veiga. Colab. Cristina Barroso... [et.al.]. Lisboa: Ministério da Educação. Available at: http://www.rbe.mec.pt/np4/file/94/lancar rbe.pdf

Rede de Bibliotecas Escolares (2010). Avaliação do Programa Rede de Bibliotecas Escolares. Coord. António Firmino da Costa ...[et.al.]. Lisboa: RBE. Available at: http://www.rbe.mec.pt/np4/file/31/978 $972 \quad 742 \quad 3194 . p d f$

Rede de Bibliotecas Escolares (2011). Modelo de avaliação da biblioteca escolar: [20102013]. Lisboa: RBE. Available at: http://www.rbe.mec.pt/np4/file/83/mabe.pdf

Rede de Bibliotecas Escolares (2012). Aprender com a biblioteca escolar: referencial de aprendizagens associadas ao trabalho das bibliotecas escolares na Educação Pré-escolar e no Ensino Básico. Coord. Elsa Conde...[et.al.]. Lisboa: RBE. Available at:

http://www.rbe.mec.pt/np4/np4/?newsId=681\&fileName=Aprender com a biblioteca escola r.pdf

Rede de Bibliotecas Escolares (2012). Aprender com a biblioteca escolar: enquadramento e conceção. Lisboa: RBE. Available at:

http://www.rbe.mec.pt/np4/file/697/aprender enquadramento.pdf

Rede de Bibliotecas Escolares (2013). Modelo de avaliação da biblioteca escolar: 20142017. Coord. Elsa Conde, Rosa Martins, Paula Ochôa. Lisboa: RBE. Available at: http://www.rbe.mec.pt/np4/file/1047/978 $972742365 \quad$ 1.pdf

Rede de Bibliotecas Escolares (2013). Programa Rede de Bibliotecas Escolares. Quadro estratégico: 2014-2020. Lisboa: RBE. Available at:

http://www.rbe.mec.pt/np4/np4/?newsld=1048\&fileName=978 $972742 \quad 366 \quad 8 . p d f$

\section{Biographical Note}

Elsa Conde has a degree in History, a specialization in Librarianship and a master's degree in Educational Sciences. She taught between 1980 and 1995. In 1997 she joined the School Library Network Program (SLNP), within which continues to exercise functions as school librarian adviser and municipal coordinator. She has collaborated in several publications of the SLNP and has accompanied various SLNP projects, like the cooperation project in Moçambique and others. She has participated in various conferences and events in Portugal 
and abroad on school libraries. She has also been a trainer in the area of libraries, especially in b-learning. 